\title{
ELECTIVE REMOVAL OF A LARGE MESENTERIC CYST - LAPROSCOPIC EXCISION.
}

KEY WORDS:

Dr.piyush Ranjan

\section{Dr. Pragya*}

Department of General Surgery, Narayan Medical College And Hospital, Jamuhar.

Department of General Surgery, Narayan Medical College And Hospital, Jamuhar.*Corresponding Author

A mesentric cyst is a rare intra abdominal benign pathology. They are found in the mesentry of small bowel (66\%) and large intestine (33\%), usually in the right colon. Very few cases have been reported of tumours found in mesentry of descending colon, sigmoid or rectum. Mesentric cysts do not show classical clinical findings and are detected incidentally during imaging due to absent or non-specific clinical presentation or during management of one of their complications. Optimal surgical management requires complete excision of the lesions. Although they are invariably benign, a full laparotomy has been the conventional approach for resection, often via a large midline incision. The advantage of minimally invasive surgery has allowed resection of the cysts, without need for a full laparotomy, with the benefit of improved cosmetics, less postoperative pain, and shorter hospital stay. However, laparoscopy can be technically challenging with large intra abdominal cysts. This is mainly due to lack of intra abdominal space and poor ergonomics in relation to port placements with large cysts. We report the incident of a 44-year-old female. A USG and computed tomography scan followed to help diagnose the lesion as a cyst. She underwent laproscopic removal and the cyst was enucleated intact. Postoperative period was uneventful and pathological examination showed a benign mesentric cyst

Objectives of this study is to analyze our experience with emphasis on the presentation, management, and outcome. Laproscopy not only helps in diagnosing the site and origin of the mesentric cyst but also has a therapeutic role.Laproscopic treatment of mesentric cyst is a safe, preferred method of treatment and is a less-invasive surgical technique. Here, we present an unusual case of mesentric cyst arising from Ascending colon treated by laproscopic excision.

\section{INTRODUCTION}

Mesentric cysts are rare pathologic entities. First reported in 1507 by Beneviene or Benevenni, $\{1\}$ now they are identified in about 1 out of 100000 adult hospital admissions. $\{2-5\}$ About half of them are chylous cysts, first described at necropsy by Rokitansky in 1842.\{6\} Although often asymptomatic, they can sometimes reach such a volume as to cause pain abdomen, bowel obstruction, and other aspecific symptoms. Mesentric cysts are usually diagnosed with imaging modalities like USG, CT scan or MRI, which determine the exact site of the cyst but cannot detect the cyst origin. Laparoscopy plays a vital role in the diagnosis of cyst, its site, origin and has a therapeutic role in the same sitting. Surgical excision of the cyst is the treatment of choice. In addition, they may mimic other abdominal diseases, such as tumors, benign masses, and congenital anomalies. The mainstay of therapy is the complete surgical removal of the cyst. This report deals with the case of a benign mesentric cyst treated by laparoscopy.

\section{CASE REPORT}

A 44 year old female patient was admitted under department of surgery with pain abdomen off $\&$ on over 4 years, and aggrevated since last 8 months duration, located in the lower abdomen which was insidious in onset and colicky in nature lasting for 15 to 30 minutes, \& pain aggravated on taking food and relieved after passing stools and anti-spasmodic medication. It was associated with abdominal distension and no $\mathrm{h}$ /o nausea, vomiting. On admission the patient was stable with a blood pressure of $110 / 70$ and pulse rate of 78 beats per minute and was afebrile. On examination, abdomen appeared to be distended with laxity of abdominal wall and an ill-defined non tender mass could be felt in the whole abdomen without any organomegaly. Pelvis free and per rectal examination revealed no abnormalities. Other systemic examinations were normal.

Laboratory tests revealed Haemoglobin (Hb)- $12.9 \mathrm{gm} \%$, Total Leucocyte Count(TLC) - 7000 cells/cumm, platelet $2,86,000$ cells/cumm, creatinine $-0.9 \mathrm{mg} \%$, Random Blood Sugar(RBS) - 76 mg\%, Erythrocyte Sedimentation Rate(ESR) $20 \mathrm{~mm}$ at end of $1^{\text {st }}$ hour. Chest $\mathrm{x}$-ray was normal. Ultrasonography (USG) of abdomen showed Large cystic lesion without any mural content or internal septation in abdominopelvic cavity obscuring the visualisation of stomach, bowel loops and hepatic parenchyma most likely of ovarian origin.

CT whole abdomen(fig 1\&2) shows- (i) A large well defined cystic lesion measuring $25 * 26 \mathrm{~cm}$, without any mural nodule or septations. Lesion is extending upto the supra-umblical region and in the pelvis and is causing mass effect upon the adjacent bowel loops. Both the ovaries are visualised separately. Overall features suggestive of mesentric or omental cyst. (ii)Bilateral normally excreting kidney without any evidence of calculi and hydronephrosis.

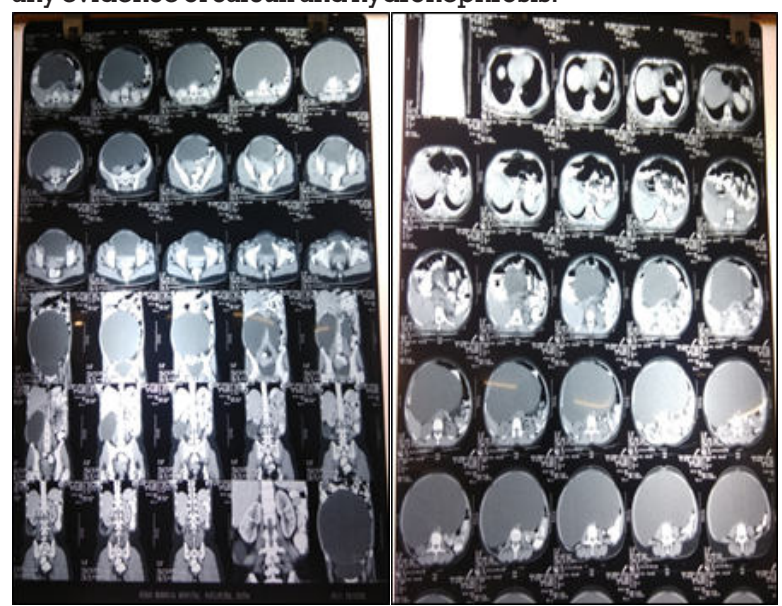

Figure-1\&2 : CTWHOLE ABDOIMEN

After all investigations she was probably diagnosed with huge mesentric cyst and was planned for elective surgery for laproscopic removal of the cyst.

- Operative notes- Under aseptic precautions part was painted and draped. Under GA, a $5 \mathrm{~mm}$ port was placed in left hypochondrioum with visualisation, $2^{\text {nd }}$ port of $5 \mathrm{~mm}$ placed in umbilical region, next $10 \mathrm{~mm}$ port placed in right and left iliac fossa. A huge cyst was found in abdomen extending from epigastrc region to pubic region, originating from the mesentry.(fig-3\&4) Suctioning of the cyst was done and about 9 litres of fluid drained out. 
Mesentic cyst was separated from adjacent structures and adhesions and finally excised, taken out through the left $10 \mathrm{~mm}$ port. Hemostasis was achieved at all steps of the procedure, a drain placed in pelvis through left $10 \mathrm{~mm}$ port. All port site closure done with ethilon 2-0 suture and antiseptic dressing done.

The post-operative period was uneventful. The patient was reviewed following discharge and he was asymptomatic and relieved of all previous symptoms. Post operatively she was managed well with $\mathrm{i} / \mathrm{v}$ antibiotic coverage, analgesics and anti-emetics \& adequate fluid resusscitation.

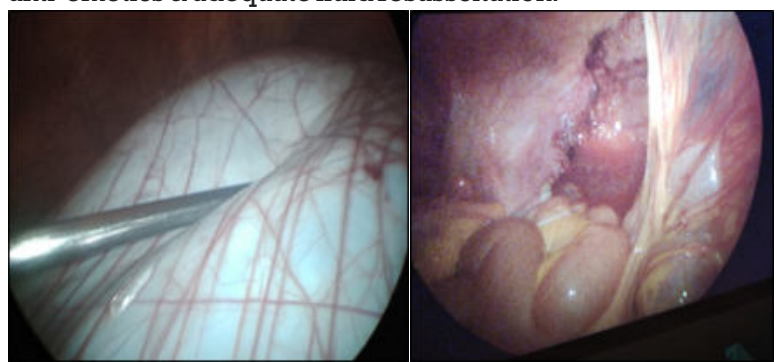

Figure-3,4:Intra op finding showing huge mesentric cyst.

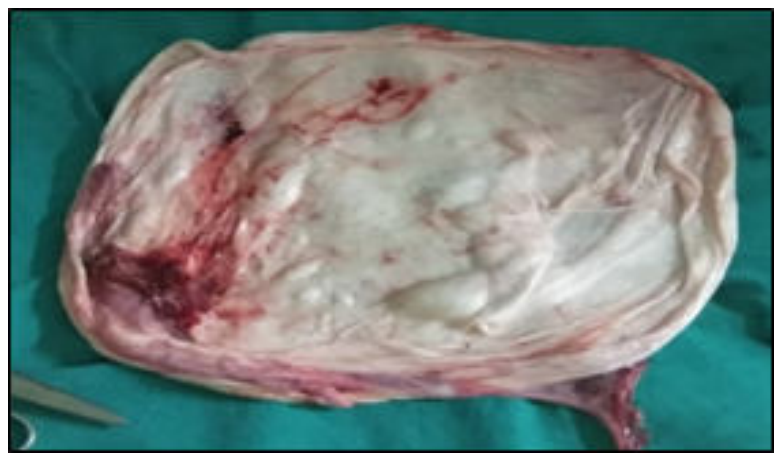

Figure-5: Excised mysentric cyst

The excised intact mysentric cyst tissue specimen(fig:5) was sent for histopathological examination, which confirmed a benign mesentric cyst.

\section{DISCUSSION}

Mesentric cysts are rare abdominal pathologic entities, discovered in about $0.001 \%$ of all adult hospital admissions in the USA.(2-5) About half of them are chylous cysts. According to dePerrot et al,(4) other mesentric cysts may be of mesothelial, enteric, dermoid, urogenital, traumatic, or infectious genesis. Malignant changes occur in less than 3\% of cases.(7) Chylous cysts are often congenital but may be related to previous abdominal surgery, pelvic diseases, and trauma. $(2-5,8,9)$ Mesentric cysts are uncommon benign tumours with an incidence of $1 / 10,500-25,000$ adult surgical patients. (10) The aetiology of mesentric cyst is variable. $[11,12]$ These usually arise from developmental abnormalities of the mesentric lymphatics or from their traumatic rupture. Simple lymphatic and mesothelial cysts are most likely congenital, while the benign cystic mesothelioma is frequently associated with a history of previous pelvic inflammatory process or surgery and endometriosis.[12]

Mesentric cyst occur with very small incidence, usually in fifth decade and with female predominance. Cystic lymphangioma is the only exception that mostly occurs in the first decade of life (up to 12 yrs of age) with male predominance.[12] Mesentric cysts are mostly asymptomatic and if present, symptoms are quite non-specific.[13] Most of these cysts are discovered incidentally during an abdominal imaging done for another reason. USG and CT scan can distinguish between solid and cystic characteristics of abdominal mass. MRI is most accurate in the diagnosis of the cyst origin as compared to CT scan.
Surgical excision of mesentric cyst is the preferred method of treatment.[14] Recently laproscopic cyst excision or resection have been advocated in many centres and is welldocumented. There are no larger series of laproscopic excision of mesentric cysts done to allow more thorough evaluation of this technique. Shimura et al. has reported two cases of successful resection of mesentric cysts (cyst contents were aspirated before excision for easy handling) located in mesentry of caecum and ascending colon. Vu et al. have also documented total laproscopic excision of mesentric cyst where cyst content was aspirated after adequate mobilization for easy extraction. Dursun et al. have reported a case of laproscopic enucleation of mesentric cyst of ileum. Depending on the size and site of mesentric cyst where difficulty is faced for easy handling, aspiration of cyst is done initially or at a later stage to ensure safe and complete excision in order to prevent recurrences or risk of malignant transformation.

\section{CONCLUSION}

Mesentric cysts, although quite rare tumors of the mesenterium, must always be considered in differential diagnosis of pelvic cystic lesions. Laproscopic enucleation of mesentric cysts is feasible and should be considered as the treatment of choice. The decision regarding the surgical approach depends on the size of the cyst, its location in the abdominal cavity and eventually the level of surgeon's experience in minimal access surgery. In this case, we considered laproscopic removal of the cyst as the treatment of choice.

\section{REFERENCES}

1) Martin WL, Grotzinger PJ, Zaydon TJ. Chylous cyst of the mesentry. Ann Surg 1954;140:132-135.

2) O'Brien MF, Winter DC, Lee G, Fitzgerald EJ, O'Sullivan GC. Mesentric cysts. A series of six cases with a review of the literature. Irish J Med Sci. 1999;168:233236.

3) Kurtz RJ, Heimann TM, Holt J, Beck AR. Mesentric and retroperitoneal cysts. Ann Surg. 1986;203:109-112.

4) dePerrot M, Brundler MA, Totsch M, Mentha G, Morel P. Mesentric cysts. Towards less confusion? Dig Surg. 2000;17:323-328.

5) Kwan E, Lau H, Yuen WK. Laproscopic resection of a mesentric cyst. Gastrointest Endosc. 2004;59:154-156.

6) Levison CG, Wolfssohn M. A mesentric chylous cyst. Cal West Med. 1929;24:480-482.

7) Liew SC, Glenn DC, Storey DW. Mesentric cyst. Aust N Z J Surg. 1994;64:141744.

8) Wykypiel HF, Margreiter R. Chylous cyst formation following laproscopic fundoplication. Wien KlinWochenschr. 2007:119(23-24):729-732.

9) Sarli L, Cortellini P, Pavlidis C, Simonazzi M, Sebastio N. Successful management of para-aortic lymphocyst with laproscopic fenestration. Surg Endosc. 2000; 14:373.

10) Kwan E, Lau H, Yuen WK. Laproscopic resection of a mesentric cyst. Gastrointest Endosc 2004;59:154-6.

11) Al Mulhim AA. Laproscopic excision of a mesentric cyst during pregnancy. JSLS 2003; 7:77-81.

12) Dursun AS, Gokhan A, Volkan S, Osman S, Cigdem T, Osman ND. Laproscopic enucleation of mesentric cyst:A case report. Mt Sinai J Med 2006:73:1019-20.

13) Iida T, Suenaga M, Takeuchi $Y$, Kobayashi T, Tobinaga J, Sakai M. Mesentric pseudocyst of the Sigmoid Mesocolon.J Gastroenterol 2003;38:081-5.

14) Shamiyeh $A$, Rieger, Schrenk P, Wayand W. Role of laproscopic surgery in resection of mesentric cyst. Surg Endosc 1999; 13:937-9. 